\title{
A Critique of Transcendental PhenOMENOLOGY
}

\author{
Tim KlaAssen (10688420)
}

There is something really exciting and intriguing about Husserl's phenomenological philosophy. In his works one reads about a newly discovered land, an "infinite field of transcendental experience", ready to be explored. ${ }^{1}$ It is the promised land that philosophers since long have been searching for in their pursuit of true knowledge. It is a place in which the essences of things reveal themselves in pure self-evidence, a place made of certainty. And the best part: it is already there, freely available in the immediacy of one's own consciousness.

I am not trying to ridicule Husserl here. To the contrary, intuitively I resonate with much of what he has to say. The phenomenological method, in particular the so-called 'phenomenological reduction', his emphasis on intentionality, and the underlying philosophical motivations that are related to it; they seem to me to make up a beautifully coherent and convincing story. However, when I think Husserl's phenomenological theory through, certain worries enter my mind that concern whether or not phenomenology can really live up to its promises.

In this paper I want to address the place of truth and realism in Husserl's phenomenology. Truth and realism were important underlying motivations for Husserl in the development of his phenomenological framework. However, I believe that ultimately these two notions are essentially problematic from Husserl's phenomenological perspective.

First I will explain the notions of truth and realism, in particular how Husserl conceived of them. Secondly, I will introduce Husserl's notion of 'absolute givenness' and his method of 'phenomenological reduction'. I will propose that the idea of absolute givenness is of crucial importance to the notions of truth and realism as conceived by Husserl. Then, in the third section, I will try to show that Husserl's theory of intentionality ultimately renders this notion of absolute givenness deeply problematic. Consequently, truth and realism collapse. ${ }^{2}$ I will finish with a short concluding remark.

\footnotetext{
${ }^{1}$ (Husserl, 1960, p. 31)

${ }^{2}$ I don't claim that my interpretation of Husserl's account of intentionality, and his phenomenological framework in general, is the only possible one. My only contention is that if we understand phenomenology in the way that I will present it (an interpretation that I take to be plausible), then it will have important (and devastating) repercussions
} 


\section{Truth, realism, and Husserl's phenomenological motivations}

Husserl understands his phenomenology to be a perfection and completion of the Cartesian project of finding an absolute grounding of knowledge (Husserl, 1960). It is therefore not controversial to say that his motivations are mainly epistemological. Husserl talks about the foundational crises of the natural sciences and the absence of any "objectively valid results" in philosophy (Husserl, 1960, p. 5). His phenomenological system can be seen as a response to these issues.

How does Husserl conceive of the idea of grounding knowledge absolutely, and how does he think we can arrive at such a ground? In the first meditation of the Cartesian Meditations Husserl elaborates extensively on these questions. One very important demand in the search for absolute grounds, according to Husserl, is that we should start without any philosophical presuppositions whatsoever. Indeed, we might not even presuppose the possibility of an absolute grounding. But then how is any progress to be made?

According to Husserl we should first look at the idea of 'grounding something' itself. Basing himself on the de facto practices of the sciences of his day, he states that 'grounding' ultimately means that we base our judgments on evidence. Husserl explains 'evidence' as a "mental seeing of something itself" (Husserl, 1960, p. 12). Moreover, the evidence proper to a philosophical grounding of knowledge must be "apodictic and first in itself" (Husserl, 1960, p. 14-16). This means for Husserl (as it also did for Descartes) that philosophy should first find something that is "absolutely given" and as such "indubitable".

Two important metaphysical notions that seem to play in the background of Husserl's phenomenological project are (1) truth as correspondence, and (2) realism. For example, in Investigation VI of Logical Investigations vol. 2 Husserl characterizes truth as adaequatio rei et intellectus, which means that truth consists in the agreement between thought and object (Husserl, 2001a, p. 260-261). Also, as we will see, phenomenology consist mainly of phenomenological descriptions. And naturally, descriptions are supposed to be capable of being more or less adequate to what they describe. Consequently, phenomenological descriptions ought to be capable of being qualified as true or false.

The idea that Husserl is a realist might be less immediately obvious. This is mainly because realism is usually understood to stand for the metaphysical doctrine that says that objects exist materially and independent from the mind, and this doctrine is, as we shall see, quite foreign to Husserl's thought. However, in the present context I will understand realism along Dummettian

for the notions of truth, realism, and the possibility of phenomenology. 
lines (Dummett, 1978): i.e. realism is a position one takes with respect to a certain class of entities. Further, and more importantly, statements about the class of entities about which one is a realist are characterized by bivalence. This means that statements about the class of entities are either true or false independently from how we think or describe these entities. In this sense then, I take Husserl to be a realist about ideal entities, and more importantly, the phenomenological data of phenomenological descriptions. ${ }^{3}$

In the remainder of this paper I will try to show why I think the notions of truth and realism, two notions that on the present account are obviously closely related together, are problematic within a Husserlian phenomenological framework. Although truth and realism seem to be two of the main forces behind Husserl's phenomenological project, the very nature of Husserl's phenomenological framework renders them deeply problematic.

\section{Absolute givenness and the phenomenological reduction}

In the Cartesian Meditations Husserl states that the "first methodological principle" of philosophy is that, in the search for an absolute grounding of knowledge, we may not accept or adhere to any assertion that is not derived from evidence (Husserl, 1960, p. 13). More specifically, the evidence that we are looking for must, in a Cartesian fashion, be absolutely given and as such be indubitable.

To understand how Husserl conceives of the notions of 'absolute givenness' and 'indubitable', it will be helpful if we pay a quick thought to Descartes methodological doubt in the Meditations on First Philosophy. Descartes famously argues that although he can doubt the existence of the world, he is absolutely certain of his own existence as a thinking thing. Now although Husserl is really not concerned which such existential problems, he does recognize in the ego the "ultimate and apodictically certain basis for judgments" (Husserl, 1960, p. 18). However, he does something very different with it.

Husserl not only thinks that the bare 'I AM' of the ego is absolutely given, he also thinks that the entire realm of conscious experience can be disclosed as something that is indubitably and absolutely given. Just as Descartes showed that we may doubt this or that, but that the fact of doubting itself cannot coherently by doubted, Husserl states that a similar principle holds for all conscious acts:

\footnotetext{
${ }^{3}$ In (Moran, 2008) we read: "Husserl Husserl maintained a robustly realist view of truth". He then cites Husserl: "What is true is absolutely, intrinsically true: truth is one and the same, whether men or not-men, angels or gods apprehend and judge it." (Husserl, 2001b, p. 79)
} 
However I might perceive, imagine, judge, infer - whether these acts are attended by certainty or uncertainty, whether they actually have objects or not - it remains absolutely clear and certain that with respect to perception I am perceiving this or that, that with respect to judgment, I am judging this or that, etc. (...) Every intellectual experience, indeed every experience whatsoever, can be made into an object of pure seeing and apprehension while it is occurring. And in this act of seeing it is an absolute givenness. (Husserl, 1999, p. 23-24) (Italics from the original text).

Simply put, although one might on a giving occasion doubt whether what one sees is really there or not, or more drastically, whether there is any external world at all, it is at least certain that one seems to see and that there seems to appear a world to us in conscious experience. In so far as we confine ourselves entirely to what actually is present in consciousness, we will have an "infinite realm of being of a new kind" (Husserl, 1960, p. 27 ) that can function as the absolute ground of all knowledge.

However, according to Husserl a definite change of attitude is needed in order for consciousness phenomena to reveal themselves to us in their absolute givenness. This change of attitude is affected by what Husserl calls the 'phenomenological reduction'. The aim of the phenomenological reduction is to exclude from our theorizing everything that is not immanently given to conscious experience itself, but is rather 'transcendent' to it. Most importantly, what needs to be excluded is (1) all suppositions concerning the (non)-existence of the external or natural world, and (2) all suppositions about how the conscious phenomena under investigation might or might not themselves be a function of an individual organism in the natural world. In connection to this Husserl also emphasizes that phenomenology is not a species of descriptive psychology. Let me explain these points in a little more detail.

In Ideas Husserl states that whereas in the 'natural attitude' one is solely concerned with matters of fact, facts whose reality are contingent, one is in the 'phenomenological attitude' solely concerned with 'essences' whose ideal reality is necessary (Husserl, 1982, p. $\mathrm{xx}-8){ }^{4}$

From within the 'natural attitude' it seems quite natural to conceive of the conscious phenomena that enter our consciousness from moment to moment as merely contingent occurrences. It is surely conceivable that, at his very moment, one could have been in another environment having different experiences. And indeed, in so far as conscious phenomena are the primary data for the phenomenologist, it might seem strange at first

\footnotetext{
${ }^{4}$ Husserl himself talks about essences as irreal. However, he means by this that essences do not exist spatio-temporaly. Yet he would nevertheless consider them 'real' in the sense that he is a realist about them (in the sense of realism that I have stipulated in the first section).
} 
that Husserl thinks that the phenomenologist is nevertheless able to deal with 'universal essences' only. According to Husserl however, the contingent mental phenomena that enter our minds precisely reveal themselves, after the performance of the phenomenological reduction, as the very essences of things themselves.

To understand how Husserl thinks this works, consider the following passages from The Idea of Phenomenology:

I have a particular intuition of red; I attend to pure immanence alone; I perform the phenomenological reduction. I separate off anything that red might signify that might lead one to apperceive it as transcendent, as, say, the red of a piece of blotting paper on my desk, and the like. (...) If we in fact do this in a pure act of seeing, would it still make sense to doubt what red in general is, what is meant by "red", what it is according to its essence? We see it - there it is; there is what we mean, this species red. Could a divine being, an infinite intellect, do anything more to grasp the essence of red than to see it as a universal? (Husserl, 1999, p. 42)

Andrew Bell clarifies this idea through a comparison with Frege (Bell, 1999). Frege distinguishes between the semantic sense of a proposition and the actual act of asserting its truth. Although a proposition might be true or false, and is usually with respect to its truth-value contingent, it's sense is independent from its actual truth value. In this sense we could say that a propositional content has its own fixed meaning independent from how the world actually is, indeed that it has its content independent from the existence of any world at all. But, and this is important, this does not mean that no reference is being made to an actual world; that such reference is not part of the content of the proposition. To the contrary, propositions essentially make reference to the world. However, from the fact that a proposition purports to refer in this a way, it does not follow that it must automatically be true. Consequently, we can consider propositional contents independently from their actual truth values.

According to Husserl, when we perform the phenomenological reduction we abstract from the fact that the contents of consciousness are contingent and may, above all, not even refer to anything existing objectively. Instead, after the phenomenal reduction, we are solely concerned with conscious phenomena qua ideal contents, i.e. eidetic essence. ${ }^{5}$ Again however, and importantly, the external world may still be part of the contents that the phenomenologist is investigating. ${ }^{6}$ However, he does not pass judgments about their contingent truth-value as (possibly non-existing) matters of fact.

\footnotetext{
${ }^{5}$ See also e.g. (Husserl, 1960, p. 27-28)

${ }^{6}$ See also (Zahavi, 2004) for discussion.
} 
Another important feature of these contents is that they are essentially intentional. That is, they essentially involve references to conscious acts such as perceiving, remembering, thinking, wishing etc. And as I have already said earlier, such intentional acts are according to Husserl themselves absolutely given and indubitable. Because these contents are entirely immanent to consciousness, and absolutely given, they provide the phenomenologist with the primary data for his phenomenological descriptions.

In this way then Husserl attempts to have established realism (in the sense specified in the first section) and the possibility of truth as adaequatio rei et intellectus. Realism is established because the phenomenological data are simply and absolutely given (which means that they are what they are independent of how we think of them or describe them). And the possibility of truth is ascertained because of the correspondence between phenomenological descriptions and intentional contents. However, as I have already said, I believe there are certain difficulties with Husserl's phenomenological approach to realism and truth. And I believe this is a direct consequence of his account of intentional acts.

\section{Husserl's account of intentional acts and the process of phenomenological description}

According to Husserl, the grounding of knowledge must proceed from the intentional acts that make up consciousness. Indeed Husserl thinks that even the 'transcendent' notion of the external ultimately wholly derives its sense from these intentional acts: "Anything belonging to the world, any spatiotemporal being, exists for me...in that I experience it, perceive it, rememeber it, think of it somehow, judge about it, value it, desire it, or the like." (Husserl, 1960, p. 21). Ultimately, such concepts as 'knowledge', 'truth', 'being' also reveal themselves as having an intentional/phenomenological origin (Bell, 1999, p. 142). But how does Husserl conceive of these intentional acts?

A fundamental feature of Husserl's account of intentionality is that intentional acts are a priori directed at specific objects, and that these objects qua intentional objects are immanently present to the acts themselves in virtue of the way the acts direct themselves, see e.g. (Husserl, 2001c, p. 235) and (Husserl, 1982, p. 74)). In other words, for a specific object to be intentionally immanent to some act, is for that act to direct itself to that object. Moreover, the fact that the act has its particular object immanent to it is wholly independent from the actual existence of that object. To be sure, consider the following passage form the Shorter Logical Investigations:

I have an idea of the god Jupiter: this means that I have a cer- 
tain presentative experience, the presentation-of-the-god-Jupiter is realized in my consciousness. (...)...it does not exist at all. This does not prevent our-idea-of-the-god-Jupiter from being actual, a particular sort of experience or particular mode of mindedness (Zumutesein), such that he who experiences it may rightly say that the mythical king of the gods is present to him, concerning whom there are such and such stories. If, however, the intended object exists, nothing becomes phenomenologically different. (Husserl, 2001c, p. 216)

Andrew Bell gives a good characterization of Husserl's account of intentionality when he characterizes it as 'adverbial' (Bell, 1999, 117). For example, a thought's being directed at the god Jupiter could be reformulated as an instance of 'thinking Jupiter-ly' (to use Husserl's terminology; each of these acts constitute a 'particular mode of mindedness'). Similarly, the objects $p, q$, and, $r$ are immanently present in the intentional acts of 'remembering $p$-ly', 'seeing $q$-ly', and 'imagining $r$-ly'. In other words, the intentional objects that are immanent to consciousness are wholly determined by the way they are being directed to.

Now I believe that if this is indeed the way we should understand Husserl's account of intentionality, the supposition of absolute givenness might turn out to be rather problematic. And consequently, the same goes for the notions of realism and truth that depend on it. Let me explain why I think this is so.

To get to where I want to go, let me first draw attention to a treatment by David Cerbone (Cerbone, 2012) of certain skeptical worries that concern the possibility of assessing phenomenological descriptions for adequacy. Cerbone distinguishes two kinds of skepticism. The first of these is an epistemological skepticism. The idea here is that because the phenomenal contents of consciousness are in such a constant flux, the phenomenologist is never able to really compare his descriptions with the phenomena that he intended to describe. Consequently, he can never really know whether or not his description adequate.

The second kind of skepticism is ontological. It hold that the absolute givenness to which the phenomenologist appeals to might actually not exist. In other words, there might simply not be any fact of the matter when it comes to the issue of whether the phenomenologists descriptions are adequate or not. The descriptions that the phenomenologist comes up with might simply be nothing more than a reflection of the beliefs that the phenomenologist happens to have about his conscious states. Consequently, there is nothing that, as it were, 'backs up' these believes (i.e. there is literally no 'Gegenstand').

Note that the first of these skeptical worries relates to the problem of assuring phenomenological truth, and that the second concerns the ques- 
tion of realism. Now Cerbone responds to these worries by saying that ultimately they are not relevant to phenomenology. The reason he offers is that such questions really point to the kind of existential concerns that the phenomenological reduction is precisely designed to eliminate. Recall that the phenomenologist is not concerned with questions such as whether the external world really exists. Instead, from the phenomenological point of view the only interest is in the external world as a phenomenon appearing to consciousness. Therefore, it would be a mistake to ask whether the phenomenologists descriptions correspond to what the phenomena in question 'really' are, for it would then treat of phenomena as objectively existing realities.

Although Cerbone is right in saying that phenomenology is not concerned with 'objective existing realities', I think that his defense is entirely besides the point. For the problem of realism here is not about whether or not intentional acts exist as objective spatiotemporal individuals, but whether they are indeed absolutely given in the way that Husserl requires them. To be sure, I have defined realism as a position that one takes to a certain class of entities. More specifically, being a realist about a certain class of entities means that one holds the conviction that when it comes to propositions about the entities in question, there is a fact of the matter that determines whether these propositions are true or not. It is precisely in this sense that Husserl is to be counted as a realist. After all, the very notion of description already essentially involves the notion of adequacy. And because it is ultimately on account of what is absolutely given that descriptions are either adequate or not, Husserl's realism ultimately depends on the reality of this absolute givenness.

Now I want to argue that the whole notion of absolute givenness is incompatible with Husserl's account of intentionality. The first question we ought to ask is: how can anything be absolutely given in consciousness if what is absolutely given is essentially an intentional construct? According to Husserl's theory of intentionality, the object of an intentional act is entirely determined by the way consciousness directs itself to it through intentional act. And this seems incompatible with the supposition that intentional contents are simply given. ${ }^{7}$

Of course Husserl should respond to this and say that, indeed, it is not the object that is absolutely given but the intentional act that is directed at it. Phenomenology is about giving descriptions of intentional acts (together with the objects that they determine), but not about the objects in so far as they are separate from these intentional acts. However, I think that the absolute givenness of the intentional acts themselves is also more problematic than it seems. The reason is that as soon the phenomenologist 'directs his regard' (Husserl, 1960, p. 53) to these intentional acts, they themselves

\footnotetext{
${ }^{7}$ See also (Bell, 1999, p. 183-184)
} 
become intentional objects. In other words, as soon as the phenomenologist 'directs his regard' to the intentional acts themselves, the acts themselves are immediately shaped by the manner in which the phenomenologist is directed at them. In this way, the supposed absolute givenness of intentional acts turns out to be highly questionable. To what extent can the phenomenologist assure himself that his phenomenological descriptions are anything more than the result of pure confabulation? ${ }^{8}$

At several passages Husserl seems to be aware of this problem. For example, in the second meditation of Cartesian Meditations he deals with the issue that 'transcendental reflection' (i.e. the process by which we direct our regard to the intentional acts themselves) modifies the phenomenological data that is being reflected on (Husserl, 1960, p. 33). ${ }^{9}$ But his response to this is, I think, quite problematic: "Therewith, to be sure, an essentially changed subjective process takes the place of the original one; accordingly it must be said that this reflection alters the original subjective process. But that is true of every reflection, including natural reflection" (Husserl, 1960, p. 34). In other words, we should not worry too much about this issue, for it is only natural for acts of reflection to modify what they are directed upon. However, I take it to be obvious that this allowance is ultimately devastating to the demand that the phenomenologist should base his descriptions on what is absolutely given.

Lastly, Husserl seems to think that it is possible for the phenomenologist to take the position of a "disinterested onlooker", and he conceives of this as an act whereby the ego "splits" himself from his intentional processes (Husserl, 1960, p. 35). However, I serious doubt if this is really possible. In any case, I would not know how to accomplish such a state. As long as I am aware of my mental life, I am actively engaged with it. Again, to be reflexively aware of ones mental life is itself an intentional act, and therefore something active. But even if it were possible to take the position of disinterested onlooker, how would it be possible to actually derive from it a phenomenological description? Must not an act of cognition precede such a description? To be a disinterested onlooker is simply a thought that one thinks, and not an actual state of being. In any case, the idea that intentional acts can themselves be absolutely given to the phenomenologist turns out to be highly problematic.

Now if indeed the whole notion of absolute givenness might as well be a mere fiction, it seems that, within a phenomenological framework, the same must be said about truth and realism. First of all, if there is no such thing as absolute givenness in the phenomenological realm, then there is 'fact

\footnotetext{
${ }^{8}$ Andrew Bell puts the points nicely: In the last analysis, all that a rigorous scientist may do is describe his own intuitions; and the dogmatism and subjectivity inherent in this proposal is not in the least mitigated by the fact that those intuitions are supposed to strike him as self-evident intuitions of essence." (Bell, 1999, p. 197)

${ }^{9}$ See also e.g. (Husserl, 1982, p. 181-190)
} 
of the matter' that can account for the actual adequacy of a phenomenological description. Indeed, there seems to be nothing left to distinguish phenomenological description from mere confabulation. Secondly, because there is nothing that enable adequacy, Husserl's conception of truth as adaequatio rei et intellectus also collapses.

\section{Concluding remarks}

I have tried to give reasons for the idea that the kind of absolute givenness to which Husserl appeals to might in fact be rather problematic. As I have tried to show, this seems to be a direct consequence of his 'adverbial' theory of intentionality, which holds that intentional objects are essentially determined by the acts that are directed to them. Because Husserl's account of truth and his realism precisely depend on this notion of absolute givenness, the question is what remains of Husserl's phenomenological project. After all, the preservation of truth and realism are two of the main motivations behind this project. To solve this issue, I believe there are two options. The first is to try to show that absolute givenness is possible after all. However, this would seem to require a very different theory of intentionality (and, again, I don't claim that my interpretation is the only possible one). The second option is to give different interpretations of the notions of truth and realism within a Husserlian phenomenological framework. Perhaps, an intersubjective theory of truth, based on phenomenological consensus, might do the trick. In fact, Husserl seemed to have hinted at this approach himself (Bell, 1999, p. 226-232). Possibly such an approach is able to save phenomenology as a philosophically fruitful discipline. However, in any case I believe the most attractive features of phenomenology will be lost.

\section{References}

Bell, D. A. (1999). Husserl: The Arguments of the Philosophers. New York, NY: Routledge.

Cerbone, D. (2012). Phenomenological method: Reflection, introspection, and skepticism. In D. Zahavi (Ed.) The Oxford Handbook of Contemporary Phenomenology, (pp. 7-24). Oxford, UK: Oxford University Press.

Dummett, M. (1978). Realism. In Truth and Other Enigmas, (pp. 145-165). Cambridge, Massachusetts: Harvard University Press.

Husserl, E. (1960). Cartesian Meditations. The Hague, NL: Nijhoff.

Husserl, E. (1982). Ideas Pertaining to a Pure Phenomenology and to a Phenomenological Philosophy, Book I. The Hague, NL: Nijhoff. 
Husserl, E. (1999). The Idea of Phenomenology. Dordrecht, NL: Kluwer.

Husserl, E. (2001a). Logical investigations, vol. 2. New York, NY: Routledge.

Husserl, E. (2001b). Logical investigations, vol. 1. New York, NY: Routledge.

Husserl, E. (2001c). The Shorter Logical Investigations. New York, NY: Routledge.

Moran, D. (2008). Husserls transcendental philosophy and the critique of naturalism. Continental Philosophy Review, 41(4), 401-425.

Zahavi, D. (2004). Husserl's noema and the internalism-externalism debate. Inquiry, 47(1), 42-66. 